\title{
'END TO END' LINKAGE STRUCTURE FOR INTEGRATED IMPACT ASSESSMENT OF INFRASTRUCTURE NETWORKS UNDER NATURAL HAZARDS
}

\author{
Syed Yasir Imtiaz ${ }^{1}$, SR Uma ${ }^{2}$, Raj Prasanna ${ }^{3}$ \\ and Liam M. Wotherspoon ${ }^{4}$
}

(Submitted July 2020; Reviewed December 2020; Accepted April 2021)

\begin{abstract}
An infrastructure impact assessment process relies on the analysis of multiple types of models, the performance of individual infrastructure networks and the interdependencies between multiple infrastructure networks. Several models are developed for their specific purposes and there is a need to link these models for the assessment of natural hazard impacts on distributed infrastructures to deliver the desired outcomes on network functionality and disruption levels that are suitable to assess socio-economic impact. In this paper, an 'end-to-end' linkage structure is proposed to link different models by which various features, data standards, parameters and structures are linked in a transparent and consistent manner. The framework has adopted a dedicated knowledge discovery and data analysis process to acquire information around input and output parameters for each of these models developed by various researchers and used in risk assessment tools. The framework is illustrated by applying the step-by-step procedure towards integrated impact assessments of electricity, potable water and road networks and their interdependencies.
\end{abstract}

\section{INTRODUCTION}

The task of infrastructure impact assessment due to natural hazards relies on a number of different models representing hazard, the performance of individual infrastructure network components, collective performance of each infrastructure network and the interdependencies between multiple infrastructure networks. Software packages to address various aspects of these individual models have recently been developed [1-6]. Even though these models are developed for their specific purposes, it is fundamental to link these models and increase their uptake in hazard-impact assessments. However, at present, there is no structured framework to link different models together and there is a need to understand what is needed in the flow from one model to the next, to facilitate integrated impact assessment of infrastructure networks [7].

Impact assessment studies are generally carried out independently for each infrastructure network to model the likelihood of damage and disruption to their respective components [8]. These studies start with selecting a hazard scenario. The vulnerabilities of exposed components are usually modelled based on evidence-based damage data from past events to predict the likelihood of damage in future events. On the other hand, when there is not enough evidence-based damage data, specific vulnerability functions are developed through analytical methods or based on expert opinion. Finally, damage and recovery models are used to determine the impact of damage to the infrastructure network components in terms of the level of service (LOS) of the infrastructure networks and their time to recover. In the existing literature, there are examples of independent hazard models [9-11], vulnerability models [12-16], and damage models [17-19] for the infrastructure network components individually or the networks as a whole. But there is a need to integrate these models within a generic framework that will facilitate various linking strategies for: (i) linking fundamental models to assess the component performance; (ii) linking the performance of different components considering intradependencies within a network to assess its functionality; and (iii) linking across different networks considering their interdependencies [20,21]. This approach enables the generation of functionality and disruption of services from infrastructure networks across a region. Developing such a framework in an integrated way by linking these models can form the basis for developing Decision Support Systems (DSS) to improve the existing decisionmaking process both qualitatively and quantitatively [22]. The identification of inflows and outflows of each model type is needed to provide consistency between inputs and outputs of each of these models and create a strong linkage framework [23].

A linkage framework for integrated impact assessment of infrastructure networks is proposed through five modules to link different models and their important components, features, data standards, parameters, and structures. The proposed framework allows the models to interact by maintaining each model's strengths, and the consistency of inputs \& outputs. The framework is tested using an example test case of the Wellington region of Aotearoa New Zealand, to illustrate each module and demonstrate the validity of the framework. Here we focus on linking the electricity, potable water and road networks as they greatly determine the level of economic stability and development of a country [24,25]. The most important aspect of this framework is that it is valid for both the component and network-level linkages. The component level linkage is achieved by linking different infrastructure component models through identification of intradependencies between the components to understand the functionality of a single infrastructure network. Similarly, the independent network models, for example for electricity or potable water network, need to be linked with interdependencies models so that the network functionality and dependency characteristics can be captured when assessing infrastructure impact across a region.

\footnotetext{
1 Corresponding Author, PhD Candidate, Massey University, Wellington, y.syed@massey.ac.nz

2 Risk and Engineering Team Leader, GNS Science, Lower Hutt, s.uma@gns.cri.nz

3 Senior Lecturer, Massey University, Wellington, r.prasanna@massey.ac.nz

4 Associate Professor, The University of Auckland, Auckland, l.wotherspoon@auckland.ac.nz (Fellow)
} 


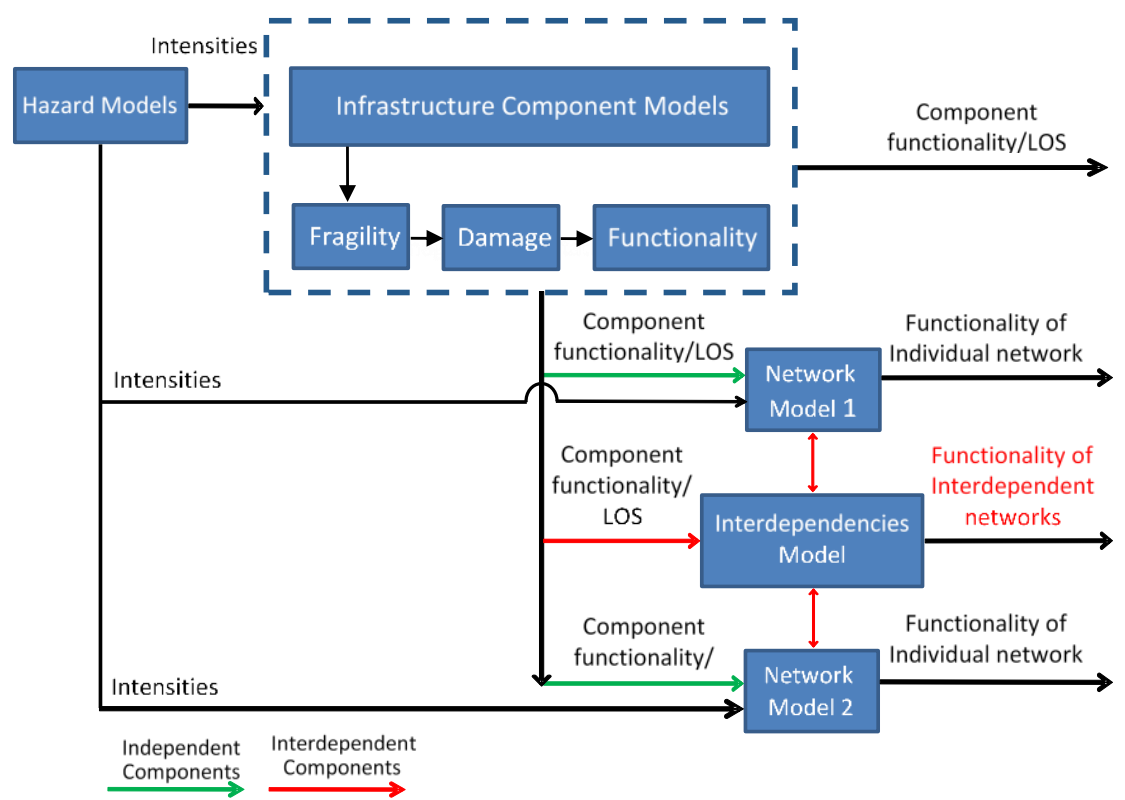

Figure 1: Schematic infrastructure impact assessment workflow demonstrating the linkages between each model. Here we have used two different network models, however, this is also applicable for a wider set of networks.

\section{INFRASTRUCTURE IMPACT ASSESSMENT}

Infrastructure impact assessment studies are usually carried out independently for each of the infrastructure networks to model the likelihood of damage and disruption to their respective components [11,26]. The disruption of infrastructure components due to a hazard can then be used to generate the level of functionality across a region. This process of hazard to functionality involves a lot of complexity due to the inherent difficulties in obtaining topological information related to the infrastructure network components, their vulnerabilities and the interdependencies. Figure 1 shows the basic building blocks of the integrated impact assessment process and schematically represents the linkages among various models (component, network, and interdependencies) to generate performance metrics related to functionality or LOS for an individual network. When the impact assessment is done for multiple infrastructure networks, there is a need to model the interdependencies to generate integrated performance metrics for other related impact assessment models. The explanation and importance of different models necessary for the infrastructure impact assessment are described next.

\section{Hazard Models}

The impact assessment workflow starts from a hazard model that can mathematically define the variation of hazard intensity across a region of interest considering the frequency and source of the hazard [8]. Historical catalogues are typically used to understand the frequency of hazard events. To associate the hazard intensity with an individual infrastructure component, high-resolution models may be necessary. For this purpose, sophisticated computational models can also be used to simulate the hazard intensities (for example, earthquake shaking, landslides, floodwater flow characteristics, tsunami overland flow depths, volcanic ash dispersion and settlement). Some models are even capable of developing synthetic event sets that represent, for example, up to 10000 years of events to provide a representation of the temporal characteristics of hazard intensities [27].

\section{Infrastructure Component Models}

These models are concerned with the damage to the significant components of an infrastructure network and are predicted using the respective hazard and fragility models. From their predicted damage, the estimated functionality of the infrastructure components can directly be generated. The important models for this process are described next.

\section{Fragility Models}

Using the fragility models, a framework assesses how much damage would occur for infrastructure components [10]. Vulnerability or fragility curves are the most common way to relate the extent of damage to hazard intensity and monetary losses [28]. The damage states describe the extent of damage and functional condition of the infrastructure components and help to estimate recovery times. However, understanding their relationships and associated uncertainties for the range of building and infrastructure characteristics of a country can be one of the major challenges and is an active research area for different hazards.

\section{Damage Models}

The damage models determine the extent of direct physical damage to an asset (e.g. buildings or infrastructure components) and are represented using definitive damage states for each of the components [8]. Depending on the damage states, one can also determine restoration time for the components of interest.

\section{Functionality Models}

The functionality models address the overall level of functionality or the LOS of the component or the whole network distributed over a region based on the damage information about each component and their connectivity [29]. This process aggregates all the information from the significant components in one place for analyzing the functionality of a network under a hazard. The functionality of components within a network can be linked through their intradependencies to determine the performance metrics for that network.

\section{Network Models}

The damage and functionality analysis of component models lead to the understanding of network functionality [29]. Network modelling is the core step of infrastructure impact assessment, which considers the possibility of multiple 
component failures and their cascading effects due to the dependency among different component models.

\section{Interdependency Models}

Most of the infrastructure networks cannot function alone and they have a strong dependency on the other networks. Therefore, analyzing interdependencies between different network models is also one of the essential steps of the infrastructure impact assessment [30-32]. From Figure 1, it is evident that for the integrated impact assessment of infrastructure networks, there are two types of linkages. The first one is to link different components within an infrastructure network through their intradependency analysis and the second linkage is between different infrastructure networks through their interdependency analysis. A framework consisting of different modules necessary for the integrated impact assessment for both linkage types is proposed and discussed in the next section.

\section{PROPOSED FRAMEWORK FOR INTEGRATED IMPACT ASSESSMENT OF INFRASTRUCTURE NETWORKS}

In this section, a unified integrated framework is presented to link infrastructure component models through intradependencies within a network and interdependencies among different networks. The framework consists of five modules that are depicted in Figure 2. The framework primarily works through knowledge discovery of the component structure, repair strategies for the damaged components and analysis of the results through identification of interdependencies. This process is needed to acquire information about the input and output parameters of the component models that are necessary to establish linkage structure at various stages of integrated impact assessment. The proposed framework is general and applicable to any infrastructure network affected by any natural hazard. The knowledge discovery process is discussed in subsequent sections of the paper through a discussion of the five modules.

\section{Module 1: Representation of Infrastructure Network Components}

The first module of the framework involves data collection for understanding the characteristics of the infrastructure networks in terms of their configuration, identification of different components, their connectivity and functional importance. For a better understanding of the regional structure of infrastructure networks, this process also involves the regional infrastructure network providers.

Module 2: Linking the Network Components through their Intradependencies

The impact assessment of an infrastructure network is largely influenced by the connectivity between the components and their functional hierarchy. Therefore, it is necessary to appropriately characterize these dependencies within an infrastructure network [5,33]. In this study, a topology networkbased approach is applied to model the performance of individual infrastructure networks and to account for their intradependencies.

\section{Module 3: Representation of Damage for the Network Components}

For impact assessment studies, hazard and vulnerability assessments are used to assess the damage states and functionality of infrastructure components. The hazard intensity measure from the hazard model is used with fragility or vulnerability models to predict damage state for the components.

\section{Module 4: Linking the Networks through Interdependencies between their Components}

When more than one infrastructure networks are modelled, there will be a need to link these networks through the identification of interdependencies between them. For this linkage, the output parameters generated from one network model should be compatible with input parameter requirements for the next model in the framework. It is necessary to identify if there are common features between the linking models, such as common input and output parameters, or common functions implemented within the models that can be helpful in the linkages. If no common features are identified, then there will be a need to develop additional linkage interfaces.

\section{Module 5: Network Functionality}

The final module in this process is to demonstrate the network functionality through the results based on the linked models.

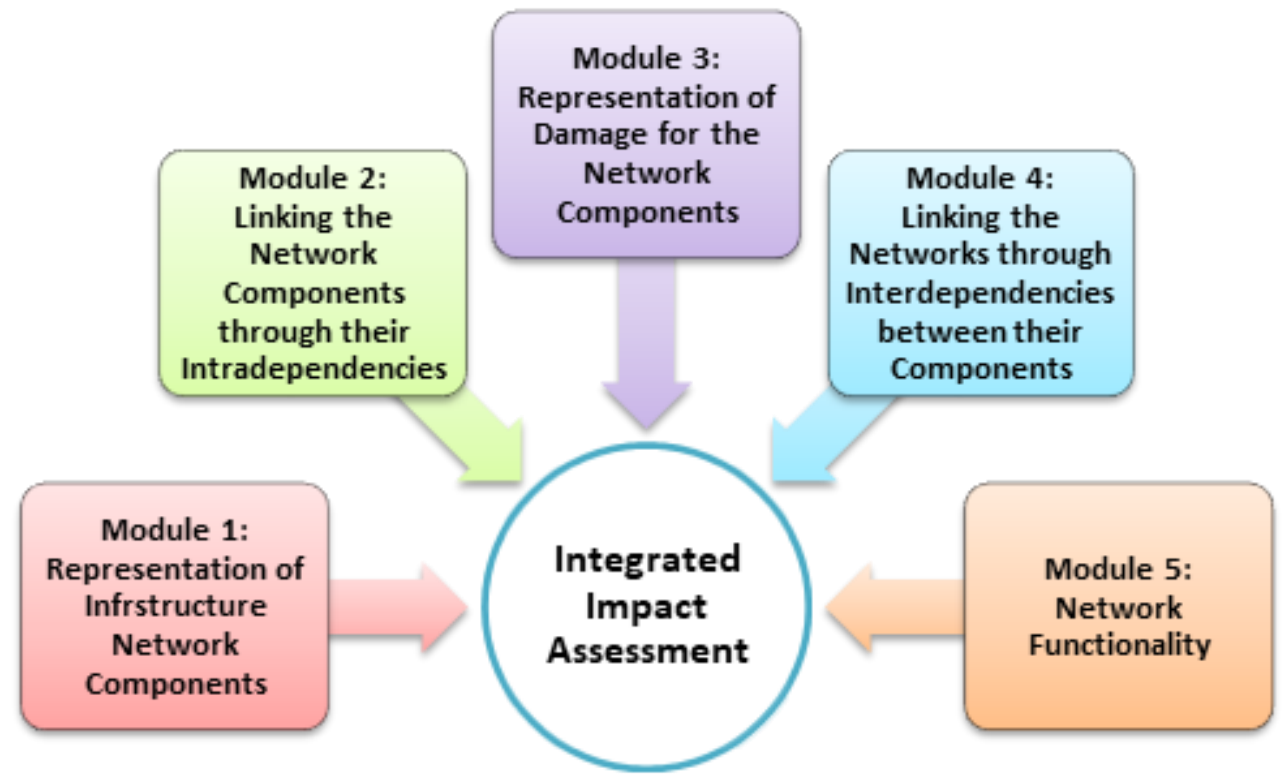

Figure 2: Proposed framework for integrated impact assessment of infrastructure networks. 
-What is the modelled network?

- What components are included in the model, and how have you characterised their functionality?

-What is the Software platform used?

- What information is needed to translate damage/functionality into inputs for your network model?

- What are the outputs of your network model?

- Have you considered any kind of interdependency model?

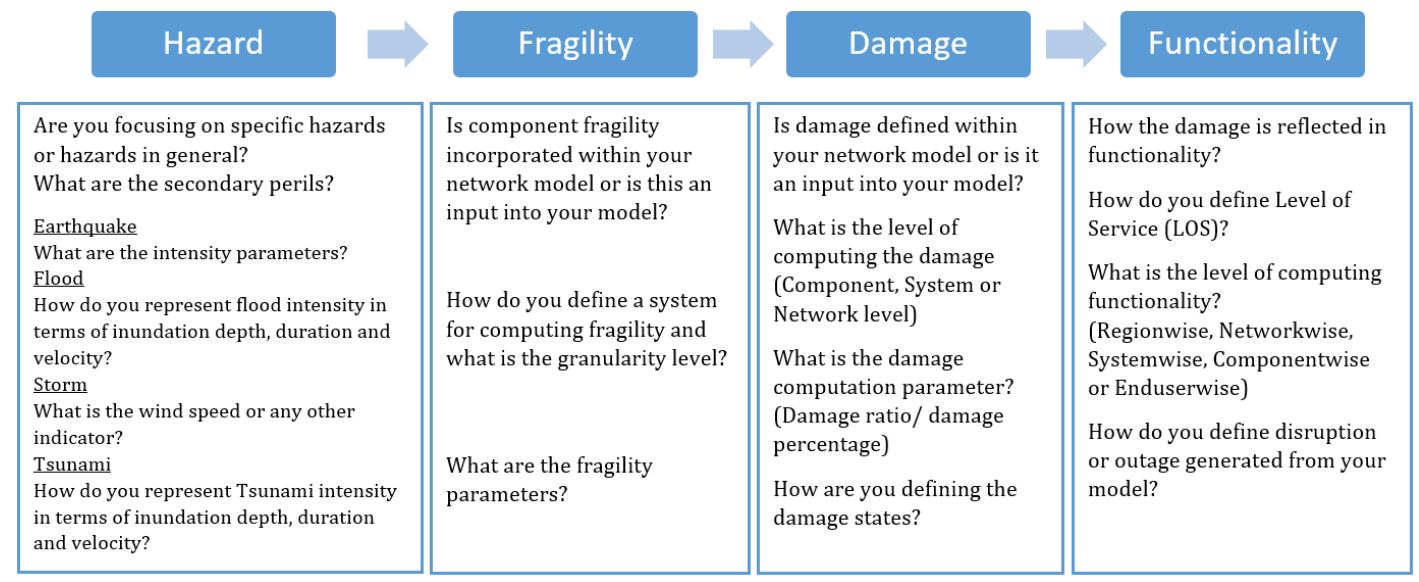

Figure 3: Interview questions used during the information gathering process.

The outputs generated from this module can be useful for future integration with additional models. Depending on the inclusion of different infrastructure networks, the detailed analysis of result can be helpful to identify the vulnerabilities in the networks and the factors influencing the delay in recovery of the network components.

\section{APPLICATION OF THE FRAMEWORK}

The proposed framework is assessed here through the integration of a range of typical infrastructure component models and infrastructure network models that were in use at the time of this study. For the application, it is necessary to collect relevant information from the current infrastructure network research, which is explained through the process adopted for knowledge discovery and data analysis. Different data collection methods and analysis can be employed to acquire qualitative data sources, which include participant observation, interviews, questionnaires, documents and texts, and the researcher's impressions and reactions [34]. This study primarily focused on infrastructure networks of the Wellington region in Aotearoa New Zealand. Wellington region is located on the plate boundary of the Pacific and Australian tectonic plates and therefore considered a region of very high seismicity [35]. The principal active earthquake faults bisect many infrastructure networks so that any future earthquake could severely affect their connectivity within the region. The earthquake faults extend into the marine area surrounding the region, creating a significant tsunami hazard from fault movement on the offshore sections of faults, or because of submarine landslides triggered by the earthquake shaking [36].

The most appropriate data collection method for this study was to use interviews for an understanding of the selected infrastructure models of electricity, potable water, and road networks. Interviews are a very effective tool for idea sharing and expressing needs between analysts and model developers [37]. The direct contact with the model developers led to a specific and constructive discussion to gather rich and detailed data relevant to this research. Depending on the need and design, interviews can be unstructured, structured, and semistructured with individual model developers [38]. For this study, the semi-structured interview technique was used as it features both closed and open questions. To be consistent with all participants, a set of core questions were designed so that the same areas could be explored with each interviewee. The different questions corresponding to the hazard, fragility, damage, and functionality models included in the semistructured interviews are shown in Figure 3. The interview responses have given insights into the input requirements and generated outputs from each of the models. These responses also helped to analyze the methodology, capabilities and limitations of these models, which helped determine how some integration might help in improving the performance of the whole system. In the knowledge discovery phase, a common structure was applied to interview various model developers for information gathering around important aspects of infrastructure impact assessment. The first important thing to understand from data collection is the knowledge about hazard scenario for the modelled network. Hazard scenarios can be earthquake, flood, storm and tsunami and they can also include the secondary perils such as fire following the earthquakes, landslide, and liquefaction. Then the component fragility related information was elicited to understand the parameters for fragility models. It is also important to identify the sources of models, that is, exogenous vs endogenous so that an appropriate linkage structure can be designed. Finally, the description of how the damage is reflected in terms of component functionality shows how model developers have generated the functionality of the network under consideration. From the collected responses, it is evident that the inflow and outflow parameters of different network component models are handled quite differently. The network performances are analysed with varying resolutions. Even though the output parameters are represented by functionality or levels of services, the output formats are different for each of the networks. The interview responses are used to apply the proposed framework by recommending a linking structure for those models that could be linked with other models.

Linking different infrastructure models can generate insights into results that otherwise would be difficult to achieve with a single network model approach $[20,39]$. The objective of using this approach is to improve the understanding of the interdependency between infrastructure networks through computer simulation. The potable water network is strongly dependent on the electricity network, as its core components such as pump stations only function when electricity is available. Some components of an electricity network also need water for cooling their equipment. The road network is critical during the restoration of damaged components of the electricity and potable water network. Damage maps of road network components and their links can enable estimates of road access 
Electricity Supply Zones of the Wellington Region

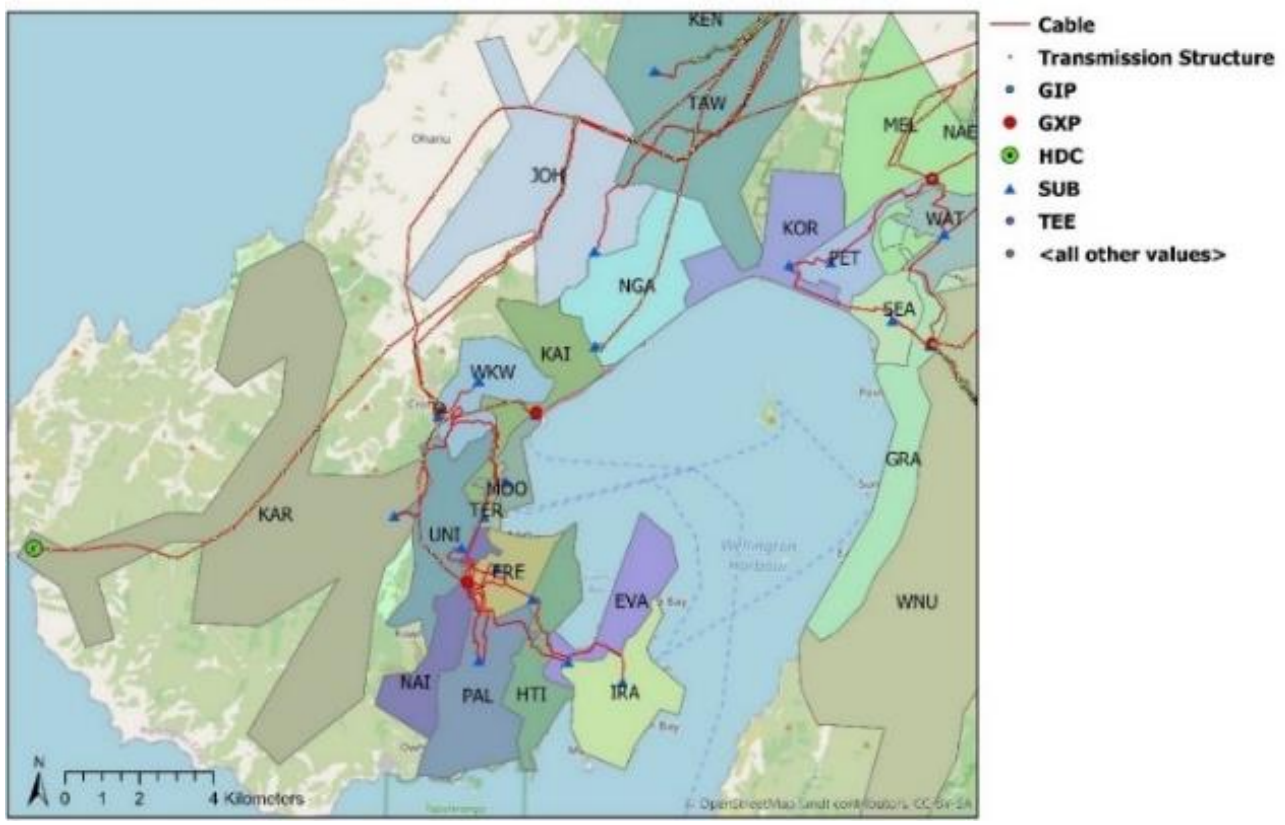

Figure 4: Wellington region's electricity supply zones and significant components modelled for this study.

time for the restoration of electricity and potable water components.

This multi-model integration approach can take advantage of the individual strengths of different modelling approaches and combine these fundamentally different models in a way to provide a solution for integrated impact assessment. There are many existing models for individual infrastructure networks, but to understand the effects of interdependency between different networks, it is necessary to have a proper linkage structure. The linkage process of the modelled networks using our integrated impact assessment methodology is discussed below.

\section{Representation of Infrastructure Network Components}

Comprehensive datasets and access to relevant information for the infrastructure networks is a fundamental requirement to understand the basic characteristics of these networks [40]. Datasets include information around spatially distributed locations of infrastructure network components, their connectivity concerning the nature of interdependencies and vulnerability characteristics. Collecting such a wide range of information from the infrastructure network provider is usually challenging because of their privacy, security and proprietary concerns [41]. Additionally, most of these infrastructure networks are owned by private organizations and therefore some of them have restricted policies for collecting and sharing data.

The data collection phase for this study involved quantitative data related to the components of electricity, potable water, and road networks in the Wellington region. Generally, infrastructure network providers have a database of multiple metadata elements that can hold values of different types, which are usually in GIS shapefiles. The necessary data as required for this study was compiled to prepare input data for interdependency analysis. Discussions were held with infrastructure network providers of the Wellington region to understand the regional structure of their networks and the characteristics of their constituent components, as described next.

\section{Data Collection for Electricity Network}

Wellington's metropolitan power supply is delivered through electricity network consisting of $220 \mathrm{kV}, 110 \mathrm{kV}, 33 \mathrm{kV}, 11 \mathrm{kV}$ and $400 \mathrm{~V}$ network components. Transpower New Zealand network consists of a series of grid exit points (GXPs) from which Wellington Electricity (WE) receives supply to deliver to commercial and domestic users. Different GXPs are connected through high power $110 \mathrm{kV}$ cables passing through transmission structures, and the supply from GXPs to substations is connected through $33 \mathrm{kV}$ overhead or buried subtransmission cables [42]. Each substation supply zone can be portrayed at meshblock level as shown in Figure 4. Statistics New Zealand [43] defines a meshblock as: "A meshblock is both a geographic unit and a classification. It is the smallest geographic unit for which Stats NZ reports statistical data. A meshblock is a defined geographic area, varying in size from part of a city block to large areas of rural land. Meshblock is contiguous: each meshblock borders on another to form a network covering all New Zealand, including coasts and inlets".

\section{Data Collection for Potable Water Network}

Wellington's potable water network consists of two parts: (i) the bulk water supply network and (ii) the reticulation network. The bulk water network components including reservoirs, treatment plants, pump stations and their respective connecting pipelines have been modelled in this study. All input and damage data of connecting pipelines between treatment plants to pump stations and from pump stations to reservoirs is represented using placeholder values, due to the sensitivity of the original data and the consequent results being generated. The pipelines that are part of the reticulation network down the reservoir are beyond the scope of this study. Figure 5 shows some part of the potable water network of the study area in which bulk water treated in the treatment plants is supplied to reservoirs through pumps stations and finally carried to the household and businesses within the potable water supply zones, represented as meshblocks. 
Water Supply Zones of the Wellington Region

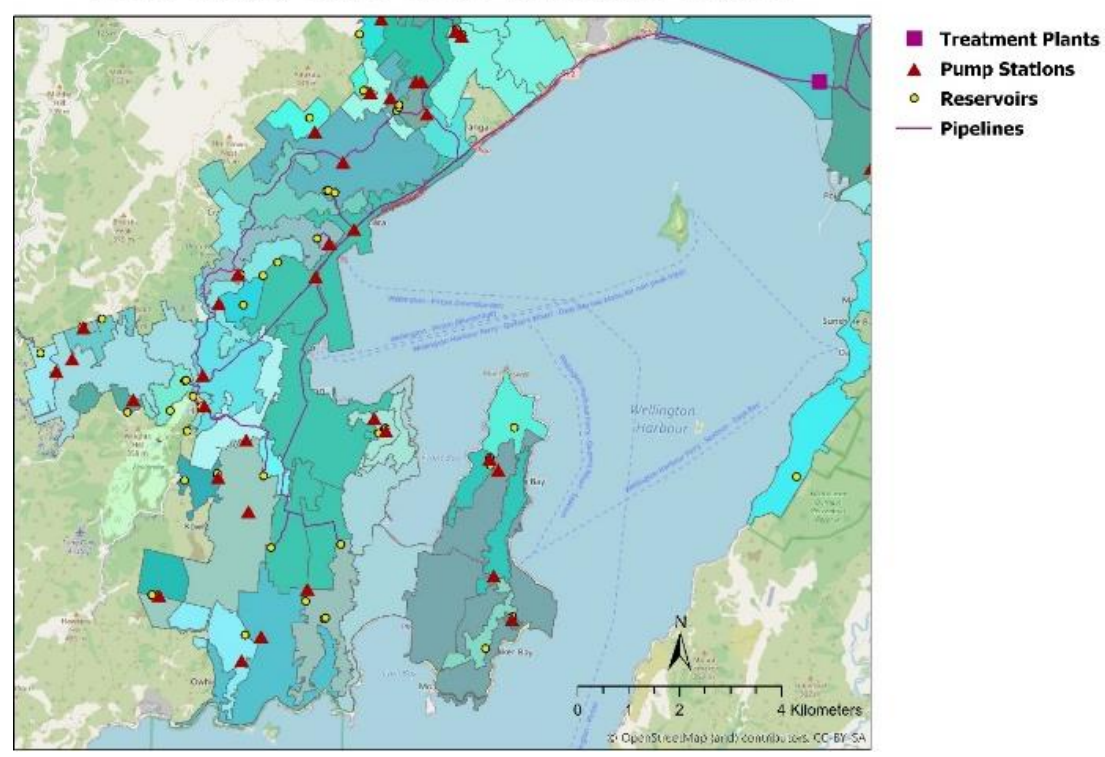

Figure 5: Wellington Region's potable water supply zones and significant components modelled for this study.

\section{Data Collection for Road Network}

A road network consists of many significant components, including road carriageway, supporting structures, retaining walls and tunnels. Road impacts can be modelled in several ways with varying resolution. However, the role of a road network in this study is only limited to estimate access times to the damaged sites of the electricity and potable water networks in both response and recovery modes. Therefore, a simplified network of 'road zones' and their respective linkage routes has been used, as opposed to full network analysis. An expert judgment workshop was held between the New Zealand Transport Agency (Waka Kotahi NZTA), regional city councils and Opus International Consultants Limited, Wellington. Wellington Region was divided into 24 different zones, as shown in Figure 6. The GIS shapefile was then converted into a CSV file to represent a 'time to recover' matrix between the 24 road zones.

\section{Linking the Network Components through their Intradependencies}

Based on the understanding of the regional structure of the electricity, potable water and road networks of the Wellington region, the input data has been linked using a topology networkbased approach. In this approach, the point assets (e.g. a pump station in a potable water network or a substation in an electrical network) are modelled as 'nodes' and linear elements e.g. electricity cables and water pipes are modelled as 'link' or 'edge'. The input parameters for nodal elements include an identifier, component type, and the road zone in which they are located. The input parameters for link elements include an identifier, source (for example, GXP/Substation/Treatment Plant), destination (for example, Substation/Pump station/Reservoir), material (structural characteristics) and the road zones in which they are located. It is worth noting that in a real network, there can be multiple links in different paths connecting a source node and a destination node (in other words

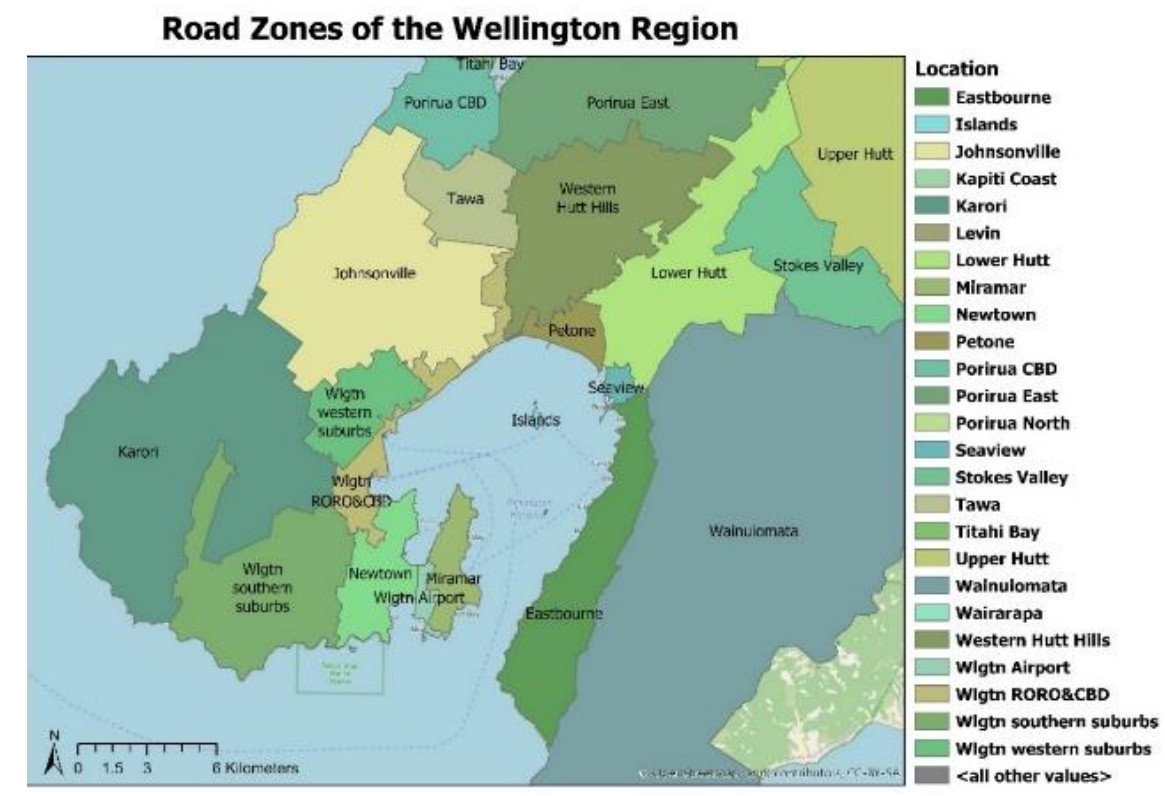

Figure 6: Wellington Region's road access zones. 
Table 1: An example of input file with the dependencies between nodes and links.

\begin{tabular}{cccccc} 
Id & Links & Source & Destination & Material & Roadzone \\
\hline $\mathbf{1}$ & NodeX-NodeY-1 & X & Y & A & RoadZone-A \\
$\mathbf{2}$ & NodeX-NodeY-1 & X & Y & A & RoadZone-B \\
$\mathbf{3}$ & NodeX-NodeY-1 & X & Y & B & RoadZone-C \\
$\mathbf{4}$ & NodeX-NodeY-2 & X & Y & A & RoadZone-A \\
$\mathbf{5}$ & NodeX-NodeY-2 & X & Y & B & RoadZone-B \\
$\mathbf{6}$ & NodeX-NodeY-2 & X & Y & C & RoadZone-C \\
\hline
\end{tabular}

'sink node') to ensure redundancy in the network. These paths can be passing through different road zones with different material types. Hence, there can be multiple entries in the input data file for each of the links following different paths as shown in Figure 7 and further explained using Table 1.

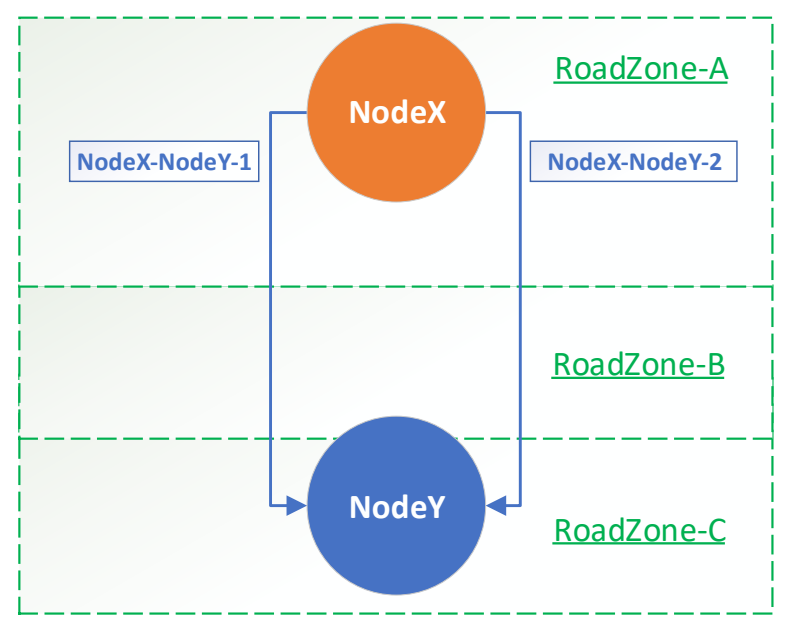

Figure 7: An example of network connectivity between nodes through multiple links.

\section{Representation of Damages for the Infrastructure Network Components}

Information related to the damage of infrastructure network components needed to be acquired from a separate hazard and risk modelling tool or software. Therefore, a risk analysis tool, namely Riskscape is used to model damage to the network components for a chosen hazard. Riskscape is a multi-hazard risk assessment software tool that estimates damage and direct losses for infrastructure network components exposed to natural hazards [2]. Riskscape generates the Damage States (DS) of different components within the identified infrastructure networks. These damage states are then used to identify outage of services due to the failure of components within a network as well as the failure of dependent components due to interdependencies between them. The final outputs are 'timestamped outage maps' that determine a network service outage area due to a hazard in different timestamps.

The process of damage assessment from Riskscape starts from modelling a hazard scenario on the infrastructure network components. It then combines spatial information on hazards, components, and their vulnerability to quantify the impacts to the infrastructure networks [2]. In this study, the Wellington Fault Mw7.5 earthquake hazard scenario including related secondary hazards such as liquefaction and ground subsidence is considered by Riskscape to model the damage. The fragility functions of Riskscape use Modified Mercalli intensity (MMI) and Peak Ground Acceleration (PGA) as the ground shaking intensity measure. A set of fragility functions is provided by Riskscape that is suitable for various types of infrastructure network components to predict their likelihood in damage states (DS1 to DS5, representing 'light' to 'extreme' damage) for a given level of hazard intensity. By modelling uncertainties in hazard and using probabilistic fragility functions, Riskscape can generate multiple damage scenarios for a network under consideration [27].

The impact to infrastructure network components that can be potential physical damage and time required to bring back lost service, is estimated with inputs from the relevant infrastructure network providers. These inputs are the decisions for appropriately selecting the resources and repair equipment and to give priority of repair to certain critical sites. The impact modelling includes uncertainty by considering a range of possible earthquake ground motion scenarios as well as uncertainty in the estimation of infrastructure component damage. By including this uncertainty, different impact scenarios can be generated. An example for representing the damage in different links is shown in Table 2. Each link between a source and destination contains several segments and the last 5 columns of Table 2 show the number of segments in each damage state. For example, the first row shows that for the link NodeX-NodeY-1 with source $X$ and destination $Y$, having material type $A$, passing through RoadZone- $A$ has $O$ segments in $D S 1,5$ in DS2, 15 in DS3 and 0 in DS4 and DS5. For each of these damage states, there is a different amount of time needed to repair those segments. Furthermore, there is also a limitation of the number of segments that can be repaired due to the number of available resources and repair equipment

\section{Linking the Networks through Interdependencies between their Components}

When two or more infrastructure networks are modelled, interdependencies are to be considered, as the functional status of components of a given network can be interdependent on components from a different infrastructure network. In this study, three types of infrastructure networks are included for illustrative purposes. Also, with any changes in road access times or component repair times, the algorithm calculates the updated recovery times using the shortest available path. The road zone data has been integrated with topology and damage data of electricity and potable water data at the component level to calculate the access times for each of these components if they are damaged. This process is shown in Figure 8, in which nodes EA, EB, EC and ED represent the components of the electricity network, whereas nodes WA, WB, WC, WD and WE represent the components of the potable water network. Further explanation about this integrated methodology is presented through a step-by-step process:

- Step 1: During the infrastructure network representation phase, the component data is collected for electricity, potable water and road networks. The data for the electricity and potable water networks is represented in the form of nodes and edges using a topology network-based approach. The whole study region is then divided into different road 


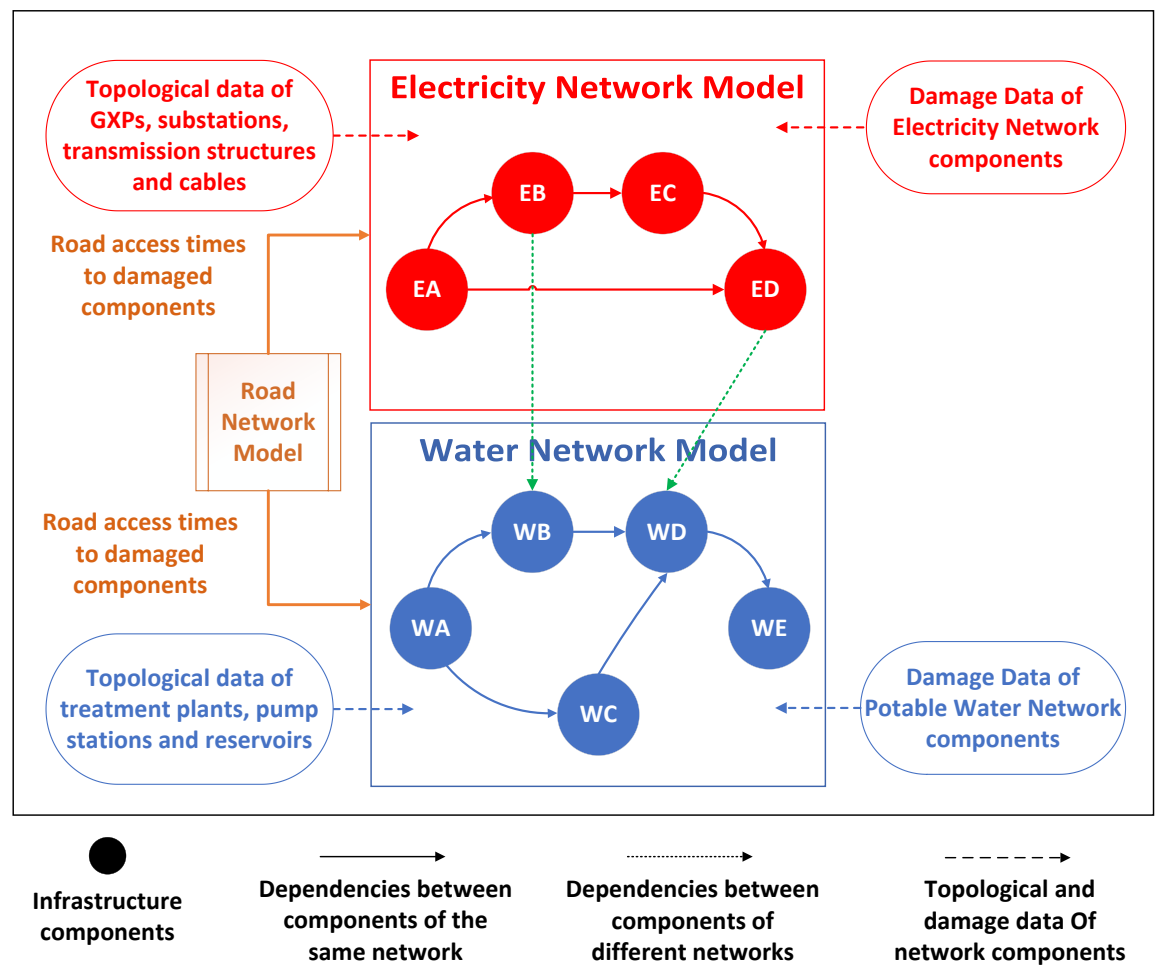

Figure 8: An integrated methodology for linking electricity, potable water, and road networks.

zones to provide further information about road access to these components.

- Step 2: During the damage representation phase, damage data for the components of the three modelled infrastructure networks (generated by Riskscape) represents different damage states for the components of the infrastructure networks.

- Step 3: The network data (topographic and damage) is then integrated using the connectivity data between the components of the modelled infrastructure networks to understand the flow of services and cascading failures of the components due to the failure to the components to which they are dependent.

\section{Network Functionality}

The conceptual integrated impact assessment framework at this stage is ready to be implemented to generate the desired results in the form of timestamped outage maps. Different modules within the framework have been designed to keep it independent from the variability of infrastructure networks and their damage models. This framework has been designed to be flexible to include more infrastructure networks easily just by including their respective damage matrices and similarly any desired damage model can be utilized to represent the damage to the infrastructure network components. Figure 9 shows an example of outage maps for the electricity network with its dependency on the road network. The mesh blocks of the

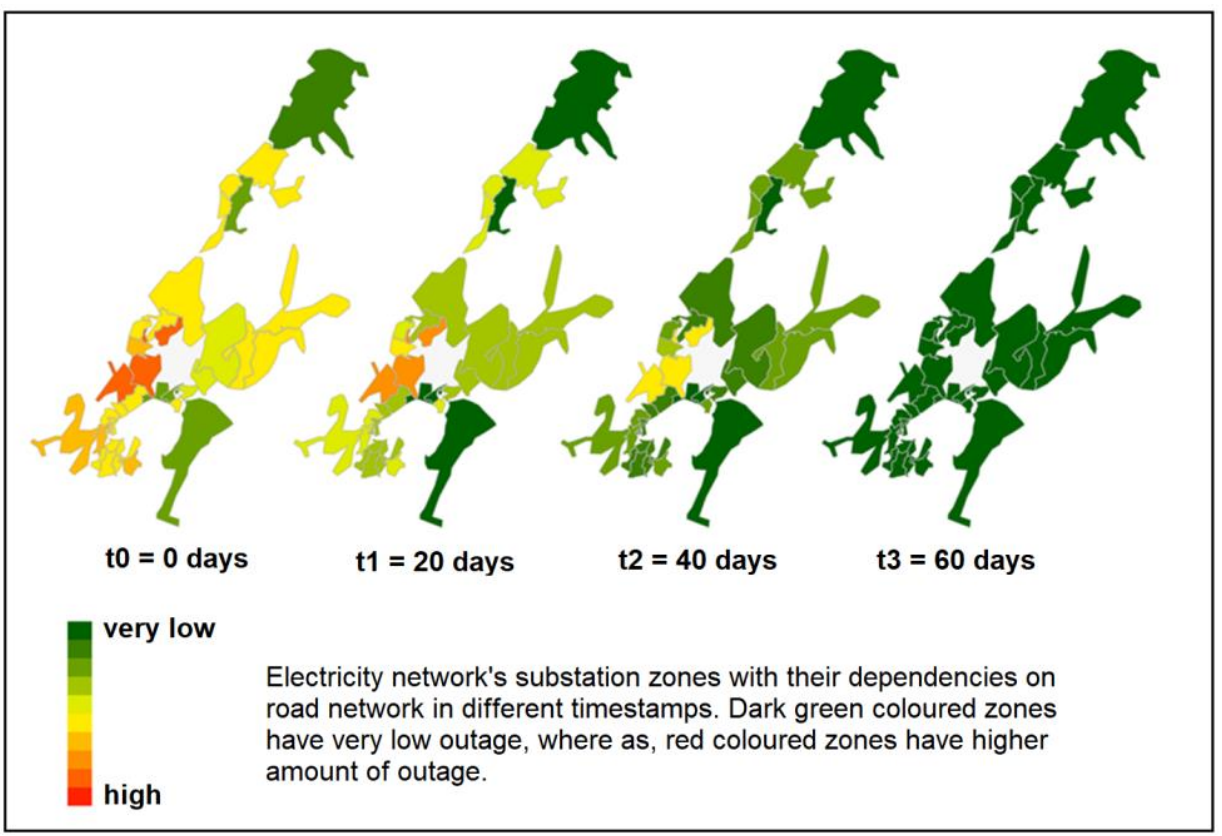

Figure 9: Timestamped outage maps generated for the example test case scenario of the Wellington region's electricity transmission network. The region is split into smaller zones, with an aggregated representation of the outage presented for each zone. 
electricity network's substation supply zones are shown in different colours where dark green zones represent very low electricity outage times and the dark red zones represent high electricity outage times.

The outage time for a substation supply zone is primarily influenced by the damage of either the substations, their source GXPs or the linking power cables and transmission structures. These outage maps show an example of the LOS of all the substation zones in the region during different timestamps, where $\mathrm{t} 0$ means the time of a hazard event and the subsequent timestamps $(\mathrm{t} 1<\mathrm{t} 2<\mathrm{t} 3)$ show the recovery electricity supply in the region. Thus, the proposed framework successfully linked GXPs, substations, transmission structures and power cables and modelled the functional dependency between them to estimate the recovery time of each supply zone of the electricity network in a region.

\section{CONCLUSIONS}

The emphasis of this paper is to define an integrated impact assessment framework for infrastructure network models. The authors have presented an integrated methodology to illustrate the applicability of the framework. This framework allows for the development of a robust and transparent method to translate results between different computational models, resulting in a more advanced and integrated or linked model. The motivation for this framework is to have a better understanding of how the models can interact, while preserving their respective strengths, and to give an improved representation of both the flows of information and the impacts of the modelled components. The five modules of the integrated framework provide an understanding of different infrastructure network components and the process to model their damages. The in-depth analysis of infrastructure network functionality with the dependencies between components of different infrastructure networks has provided some key points to be considered as below:

1. When different infrastructure network component models are linked to model a single infrastructure network, the damages or functionality impacts of one component model must be reflected in other models so that combined effects of intradependencies can be analysed.

2. An understanding of interdependencies between the components of two different infrastructure network models is crucial to interlink multiple infrastructure networks. The effort required in this process can be quite demanding, and expert elicitation is an effective approach to enable this.

3. For those models where the direct linkage is not possible, sophisticated interface models should be used to integrate across the different models.

\section{ACKNOWLEDGEMENTS}

This study is partly funded by the Resilience to Nature's Challenges National Science Challenge and QuakeCoRE, which is a New Zealand Tertiary Education Commissionfunded Centre. Post Disaster Cities (PDC) of GNS Science, New Zealand provided additional funding through its Core Research Programme. The authors are thankful to the representatives from Wellington Electricity (WE), Transpower NZ, Waka Kotahi NZTA, and Wellington lifeline utilities group (WeLG) for their feedback and support throughout this project. Furthermore, the authors are also thankful to the infrastructure model developers and researchers all over New Zealand who contributed in this research through the interviews. This is QuakeCoRE publication number E6471_17104.

\section{REFERENCES}

1 Bebbington M, Cronin SJ, Chapman I and Turner MB (2008). "Quantifying volcanic ash fall hazard to electricity infrastructure". Journal of Volcanology and Geothermal Research, 177(4): 1055-1062. https://doi.org/10.1016/j.jvolgeores.2008.07.023

2 King A, Cousins J, Heron D, Matcham I, Pringle R, Bell R, Reese S, Schmidt J and Henderson (2007). "Regional RiskScape: A multi-hazard loss modelling tool". Atmospheric Research.

3 Boulos PF, Jacobsen LB, Heath JE and Kamojjala S (2014). "Real-time modeling of water distribution systems : A case study". Journal AWWA, 106(9): 391-401. https://doi.org/10.5942/jawwa.2014.106.0076

4 Buxton R, Fenwick T, Mcdonald G, and Mieler DH (2016). "A Sectoral Level Interdependencies Model for Critical Infrastructure". GNS Science Report 2015/29, Lower Hutt, NZ, 13pp.

5 Nan C and Sansavini G (2017). "A quantitative method for assessing resilience of interdependent infrastructures". Reliability Engineering and System Safety, 157: 35-53. https://doi.org/10.1016/j.ress.2016.08.013

6 Zorn C, Pant R, Thacker S and Shamseldin AY (2020). "Evaluating the magnitude and spatial extent of disruptions across interdependent national infrastructure networks". ASCE-ASME Journal of Risk and Uncertainty in Engineering Systems Part B: Mechanical Engineering, 6(2): 1-35. https://doi.org/10.1115/1.4046327

7 Paltrinieri N, Breedveld L, Wilday J and Cozzani V (2013). "Identification of hazards and environmental impact assessment for an integrated approach to emerging risks of CO2 capture installations". Energy Procedia, 37: 28112818. https://doi.org/10.1016/j.egypro.2013.06.166

8 Chen AS, Hammond MJ, Djordjević S, Butler D, Khan DM and Veerbeek W (2016). "From hazard to impact: flood damage assessment tools for mega cities". Natural Hazards, 82(2): 857-890.

https://doi.org/10.1007/s11069-016-2223-2

9 Deligne NI (2016), "Developing volcanic hazard and risk models for the Auckland Volcanic Field as part of the DEVORA project". Final Report for EQC Project 12/U640. https://www.eqc.govt.nz/sites/public_files/4620-

Developing-volcanic-hazard-and risk-models-AucklandVolcanic-Field.pdf

10 Schmidt J, Turek G, Matcham I, Reese S, Bell R and King A (2007). "RiskScape - An innovative tool for multi-hazard risk modelling". Geophysics Research Abstracts, 9.

11 Gallina V, Torresan S, Critto A, Sperotto A, Glade T and Marcomini A (2015). "A review of multi-risk methodologies for natural hazards: consequences and challenges for a climate change impact assessment". Journal of Environmental Management, 168: 123-132. https://doi.org/10.1016/j.jenvman.2015.11.011

12 Pant R, Thacker S and Hall JW (2017). "System-of-systems framework for global infrastructure vulnerability assessments". Environmental Change Institute (ECI), GGKP Annual Conference.

https://www.greengrowthknowledge.org/sites/default/files/ downloads/resource/System-of-systems framework for global infrastructure vulnerability assessments.pdf

13 Menoni S, Pergalani F, Boni M and Petrini V (2002). "Lifelines earthquake vulnerability assessment: a systemic approach". Soil Dynamics and Earthquake Engineering, 22(9-12): 1199-1208. https://doi.org/10.1016/S0267-7261(02)00148-3 
14 Ouyang M, Hong L, Mao ZJ, Yu MH and Qi F (2009). “A methodological approach to analyze vulnerability of interdependent infrastructures". Simulation Modelling Practice and Theory, 17(5): 817-828. https://doi.org/10.1016/j.simpat.2009.02.001

15 FEMA (1991). "Seismic Vulnerability and Impact of Disruption of Lifelines in the Conterminous United States". Applied Technology Council Report ATC-25, 440pp. https://store.atcouncil.org/index.php?dispatch=attachments .getfile\&attachment_id=29

16 Zhang C, Liu X, Jiang YP, Fan B and Song X (2014). “A two-stage resource allocation model for lifeline systems quick response with vulnerability analysis". European Journal of Operational Research, 250(3): 855-864. https://doi.org/10.1016/j.ejor.2015.10.022

17 Johansen C and Tien I (2017). "Probabilistic multi-scale modeling of interdependencies between critical infrastructure systems for resilience". Sustainable Resilient Infrastructure, 3(1): 1-15.

https://doi.org/10.1080/23789689.2017.1345253

18 Bočkarjova M, Steenge AE and van der Veen A (2004). "On direct estimation of initial damage in the case of a major catastrophe: derivation of the "basic equation". Disaster Prevention and Management, 13(4). https://doi.org/10.1108/09653560410556555

19 Anil EB, Akinci B, Garrett JH and Kurc O (2016). "Information requirements for earthquake damage assessment of structural walls". Advanced Engineering Informatics, 30(1): 54-64. https://doi.org/10.1016/j.aei.2015.12.002

20 Peerenboom JP and Fisher RE (2007). "Analyzing crosssector interdependencies". 40th Annual Hawaii International Conference on System Sciences (HICSS'07), 3-6 January, Waikoloa, HI, USA. https://doi.org/10.1109/HICSS.2007.78

21 Puuska S, Rummukainen L, Timonen J, Lääperi L, Klemetti M, Oksama L and Vankka J (2018). "Nationwide critical infrastructure monitoring using a common operating picture framework". International Journal of Critical Infrastructure Protection, 20: 28-47. https://doi.org/10.1016/j.ijcip.2017.11.005

22 Klashner R and Sabet S (2007). "A DSS design model for complex problems: lessons from mission critical infrastructure". Decision Support Systems, 43(3): 9901013. https://doi.org/10.1016/j.dss.2005.05.027

23 Riekkola AK, Berg C, Ahlgren E and Söderholm P (2013). "Challenges in Soft-Linking: the Case of EMEC and TIMES-Sweden". Working Paper 133, National Institute of Economic Research, Stockholm.

24 Laprie JC, Kanoun K and Kaaniche M (2007). "Modelling interdependencies between the electricity and information infrastructures". Lecture Notes in Computer Science. http://arxiv.org/abs/0809.4107

25 Erdener BC, Pambour KA, Lavin RB and Dengiz B (2014). "An integrated simulation model for analysing electricity and gas systems". International Journal of Electrical Power and Energy Systems, 61: 410-420. https://doi.org/10.1016/j.ijepes.2014.03.052

26 Pant R, Thacker S, Hall JW, Alderson D and Barr S (2017). "Critical infrastructure impact assessment due to flood exposure". Journal of Flood Risk Management, 11: 22-33. https://doi.org/10.1111/jfr3.12288

27 Schmidt J, Matcham I, Reese S, King A, Bell R, Henderson R, Smart G, Cousins J, Smith W and Heron D (2011). "Quantitative multi-risk analysis for natural hazards: a framework for multi-risk modelling". Natural Hazards, 58(3): 1169-1192.

https://doi.org/10.1007/s11069-011-9721-z
28 Sudret B, Mai C and Konakli K (2017). "Assessment of the lognormality assumption of seismic fragility curves using non-parametric representations". Strutural Safety Journal. https://hal.archives-ouvertes.fr/hal-01432508

29 Lee S, Hwang S, Park M and Lee HS (2018). "Damage propagation from component level to system level in the electricity sector". Journal of Infrastructure Systems, 24(3): 1-13. https://doi.org/10.1061/(ASCE)IS.1943-555X.0000437

30 Panzieri S, Setola R and Ulivi G (2005). "An approach to model complex interdependent infrastructures". IFAC Proceeding Volumes, 38(1): 404-409. https://doi.org10.3182/20050703-6-CZ-1902.00068

31 Hasan S and Foliente GC (2015). "Modeling infrastructure system interdependencies and socioeconomic impacts of failure in extreme events: emerging R\&D challenges". Natural Hazards, 78(3): 2143-2168. https://doi.org/10.1007/s11069-015-1814-7

32 Lewis LP and Petit F (2019). "Critical Infrastructure Interdependency Analysis: Operationalising Resilience Strategies". Contributing Paper to the Global Assessment Report on Disaster Risk Reduction (GAR 2019), 33pp. https://www.unisdr.org/files/66506_f415finallewisandpetit criticalinfra.pdf

33 Huang CN, Liou JJH and Chuang YC (2014). "A method for exploring the interdependencies and importance of critical infrastructures". Knowledge-Based Systems, 55: 6674. https://doi.org/10.1016/j.knosys.2013.10.010

34 Creswell JW (2013). "Research Design: Qualitative, Quantitative, and Mixed Methods Approaches". Fourth Edition, ISBN: 978-1452226095, Sage Publications.

35 Mowll R, Brunsdon DR, Wilde F and Leslie PD (2013). "Understanding the impact of a major earthquake on Wellington lifelines". Bulletin of the New Zealand Society of Earthquake Engineering, 46(2): 109-115. https://doi.org/10.5459/bnzsee.46.2.109-115

36 New Zealand ShakeOut - Wellington Earthquake Hazards. http://www.shakeout.govt.nz/wellington/ (Accessed 11 August 2019)

37 Marshall C and Rossman GB (2006). "Designing Qualitative Research". Sixth Edition, ISBN: 9781452271002, Sage Publications.

38 Creswell JW (2018). "Research Design: Qualitative, Quantitative, and Mixed Methods Approaches". Fifth Edition, ISBN: 978-1506386706, Sage Publications.

39 O'Fallon C (2003). "Linkages Between Infrastructure and Economic Growth". Pinnacle Research Report prepared for Ministry of Economic Development, Wellington, 14pp. https://citeseerx.ist.psu.edu/viewdoc/download?doi=10.1.1 $.184 .9839 \&$ rep $=$ rep $1 \&$ type $=$ pdf

40 Chou CC, Tseng SM and Ho TW (2009). "Data collection and analysis of critical infrastructure interdependency relationships". Computing in Civil Engineering. https://doi.org/10.1061/41052(346)28

41 Rinaldi S, Peerenboom JP and Kelly TK (2001). "Identifying, understanding, and analyzing critical infrastructure interdependencies". IEEE Control System Magazine, 21(6): 11-25. https://doi.org/10.1109/37.969131

42 Mowll R (2012). "Lifeline Utilities Restoration Times for Metropolitan Wellington Following a Wellington Fault Earthquake". Report to the Wellington CDEM Group Joint Committee from the Wellington Lifelines Group. Wellington Lifelines Group, 63pp.

43 Statistics New Zealand. Home | Stats NZ. https://www.stats.govt.nz (Accessed 10 February 2018) 